\title{
Redintegration and lexicality effects in children: Do they depend upon the demands of the memory task?
}

\author{
JUDY E. TURNER \\ University of Reading, Reading, England \\ LUCY A. HENRY \\ Institute of Psychiatry, London, England \\ and \\ PHILIP T. SMITH and PENELOPE A. BROWN \\ University of Reading, Reading, England
}

\begin{abstract}
The effect of long-term knowledge upon performance in short-term memory tasks was examined for children from 5 to 10 years of age. The emergence of a lexicality effect, in which familiar words were recalled more accurately than unfamiliar words, was found to depend upon the nature of the memory task. Lexicality effects were interpreted as reflecting the use of redintegration, or reconstruction processes, in short-term memory. Redintegration increased with age for tasks requiring spoken item recall and decreased with age when position information but not naming was required. In a second experiment, redintegration was found in a recognition task when some of the foils rhymed with the target. Older children were able to profit from a rhyming foil, whereas younger children were confused by it, suggesting that the older children make use of sublexical phonological information in reconstructing the target. It was proposed that redintegrative processes in their mature form support the reconstruction of detailed phonological knowledge of words.
\end{abstract}

The concept of redintegration has proved to be a productive approach to examining why long-term memory (LTM) knowledge affects performance on short-term memory (STM) tasks. Schweickert (1993) proposed that LTM influences the retrieval of degraded memory traces from STM, as an automatic part of speech perception and production. He suggested that phonological word forms are used in the reconstruction or redintegration of memory items and that these are more accessible for high-frequency than for low-frequency words. Novel items such as nonwords do not benefit from redintegration because they do not have LTM representations. We explore the aspects of STM which benefit from redintegration and how these processes change with age, comparing the effects of lexicality (words compared to nonwords) upon a range of STM tasks in 5- to 10-year-olds.

There are several stages during which redintegration could make contributions to recall accuracy in auditory

This research was supported by Grant R000223435 from the U.K. Economic and Social Research Council. We thank the staff and pupils of St. Andrew's School, Cobham; Hinchley Wood County Primary; Claygate County Primary; Royal Kent Church of England Primary, Oxshott; and Sandfield County Primary, Guildford. Correspondence should be addressed to J. E. Turner, University of Reading, School of Psychology, Earley Gate, Whiteknights, Reading RG6 6AL, England (e-mail: j.e.turner@reading.ac.uk). memory tasks. For example, long-term knowledge has an effect prelexically: Vitevitch and Luce (1999) found that decisions could be made more rapidly about auditory items whose constituent phoneme pairs had a high probability of occurrence in the language (phonotactic probability) than about items with low-probability sound sequences. Long-term knowledge also has an effect on item identification at a lexical level: Broadbent (1967) established that high-frequency words were more intelligible in white noise than were low-frequency words, and Turner, Valentine, and Ellis (1998) found age of acquisition effects for auditory lexical decision.

In memory tasks, redintegration could occur during rehearsal or at recall. Hulme, Maughan, and Brown (1991) found that memory span for real words was longer than for nonwords, implying that STM is influenced by lexical knowledge. This use of long-term knowledge could arise at the retrieval stage of the phonological word form for spoken recall. There may also be an effect of longterm knowledge at rehearsal since familiar items are rehearsed more rapidly than unfamiliar items. This is generally dismissed as being of trivial significance (Hulme, Newton, Cowan, Stuart, \& Brown, 1999; Hulme, Roodenrys, Brown, \& Mercer, 1995), but may reflect redintegrative processes. More rapid speech for words than nonwords may be a consequence of the production of an effective and practiced output phonology for words, lead- 
ing to the more rapid silent articulation of words than nonwords during rehearsal.

Some evidence is inconsistent with the suggestion that rehearsal is the sole locus of LTM effects. Turner, Henry, and Smith (2000) found dissociations between word length effects, generally considered to be a measure of rehearsal, and familiarity effects. The findings supported the interpretation that the familiarity effect did not arise as a consequence of rehearsal. Also the difference between memory span for familiar and unfamiliar words is present even when rehearsal is severely curtailed by the use of articulatory suppression (Gregg, Freedman, \& Smith, 1989; Tehan \& Humphreys, 1988).

When rehearsal is eliminated, redintegration may occur at retrieval or during the formation of output phonology. The lexicality effects found in tasks that require spoken output of the memory items (Gathercole, Pickering, Hall, \& Peaker, 2001; Turner et al., 2000) are much greater than those found using matching serial recognition tasks, which do not require item naming (Gathercole et al., 2001). This implies that lexicality effects are a consequence of speech production (as proposed by Hulme et al., 1997). However, we still need to rule out the possibility that lexical effects may result from the processes that generate the precise phonology that forms the basis of speech output, rather than from the speech process itself.

Turner et al. (2000) found that lexicality effects were critically dependent upon the recall demands of the memory task. Real word items were recalled more accurately than nonwords when spoken item recall was required, but there was no effect of lexicality upon recall when the task was to remember the position of an item in the list. The effect of lexicality developed with age and was attributed to development in the use of redintegrative processes. It was proposed that for the item recall task, older children and adults used long-term representations of the phonological forms of known words to assist in the reconstruction of an accurate phonology. When the task did not require the production of the item's phonology, such redintegrative processes were not used.

It is now well established that the effects of output interference produced by spoken recall vary with age and can produce spurious changes in memory reflecting the development of the output processes with age, rather than the development of storage or retrieval processes (Cowan, 1999; Henry, 1991). We therefore used a probed memory task rather than full spoken recall to reduce output interference effects and allow the locus of redintegrative effects to be investigated without this added confusion.

The lexical status of memory items, and hence the extent to which they can benefit from redintegration, can be altered by experience within the experimental context (Hulme et al., 1991; Hulme et al., 1995). Roodenrys and Quinlan (2000) found an interaction between frequency effects and the size of the item set used for the memory task. Word frequency had an effect upon recall accuracy, but the effect of the size of the memory item set was apparent only for low-frequency items: Low-frequency words were easier to remember from a small stimulus set. Roodenrys and Quinlan proposed that the use of a small stimulus set resulted in priming of the phonological representations of the memory items and allowed redintegrative processes to be more effective. Together, these results suggest that the redintegrative processes are able to make use of contextual familiarity as well as longer term knowledge to enhance reconstructive processes or influence decision making. The present investigation made use of a large item set so that the lexicality of items would be minimally affected by exposure during the experiment and so that the nonwords would remain as unfamiliar as possible.

Because we were interested in tracking developmental changes in the concept of lexicality, we included two sets of words and one set of nonwords for use in the memory tasks. The two sets of words differed in the extent to which they were familiar to 5-year-olds as measured by their accuracy on a lexical decision task, producing a set of words that were "easy" for 5-year-olds, or highly lexical, and a set of words that were "difficult," or of low lexicality.

\section{EXPERIMENT 1}

We examined developmental changes in the use of redintegration in children between 5 and 10 years of age. Is redintegration used only when precise phonological information is needed, or is it also used when the memory item does not need to be named? In Condition P, participants were required to listen to a list of items and, then, following re-presentation of one list item, recall its list position. In Condition I, participants listened to a list of items and were required to recall the item that had been heard in a particular probed serial position.

\section{Method}

Participants. Three groups of children participated in each condition. In Condition P, this included twenty 5-year-olds (mean age $=5$ years, 6 months; $S D=3.3$ months); twenty-three 7-yearolds (mean age $=7$ years, 6 months; $S D=3.1$ months); and twenty 10 -year-olds (mean age $=10$ years, 5 months; $S D=3.3$ months). In Condition I there were twenty-two 5-year-olds (mean age = 5 years, 7 months; $S D=2.9$ months); twenty-four 7 -year-olds (mean age $=7$ years, 6 months; $S D=3.6$ months); and twenty 10 year-olds (mean age $=10$ years, 4 months; $S D=3.3$ months). The children were drawn at random from two local education authority schools in Surrey, England, and were tested individually at their schools. They were screened using a test of receptive vocabulary (BPVS II; Dunn, Dunn, Whetton, \& Burley, 1997) to exclude children with standard scores of 80 or below.

Materials. Memory lists consisted of items taken from one of three word sets: easy words, difficult words, and nonwords. Each word set consisted of 23 monosyllabic items. The words were taken from a word set previously used in an auditory lexical decision task (Smith, Turner, Brown, \& Henry, 2004). The accuracy with which 5 -year-olds could make a lexical decision for each word was used to determine whether it was an "easy" or "difficult" word. Values for familiarity, age of acquisition and imageability were taken from the MRC Psycholinguistic database (Quinlan, 1992). The spoken frequency was taken from the CELEX database (Baayen, Piepenbrock, \& van Rijn, 1993). 
Words in the easy and difficult sets were matched for the number of phonemes, for spoken frequency, for imageability, for phonotactic plausibility, and for number of phonological neighbors (Goldinger, Luce, \& Pisoni, 1989). No significant difference was found between the values of these variables for the easy and difficult word sets using $t$ tests: All $t$ values were less than 1 . In contrast, comparisons of the easy and difficult word sets revealed that the easy words were of greater familiarity than the difficult words $[t(44)=2.52$, $p<.05]$ and that the easy words had an earlier age of acquisition than the difficult words $[t(44)=6.22, p<.001]$. Nonwords were selected from those items that were most consistently identified by 5 -year-olds as not being real words in the lexical decision task previously mentioned (Smith et al., 2004). Nonword item sets were matched to the items in the easy and difficult word sets for phonotactic plausibility as measured by the probability with which each consonant sequence occurs in the 1,000 most frequent one-, two-, and three-syllable words in English. A single token of each stimulus item, in a female voice, was stored in a computer and output by the computer as required. The stimulus items are listed in the Appendix.

Design and Procedure. There was one between-participants variable (recall condition, I or P) and one within-participants variable (easy words, difficult words, and nonwords). Each child took part in two sessions consisting of a block of memory lists of the shorter length followed by a block of longer memory lists. The order of sessions was counterbalanced between children. Over each block, the target occurred once in each serial position for each of the three word sets. The order of the three conditions was randomized within the blocks. There were 14 different orders for the memory items for each age group.

List lengths were chosen to be at or around average memory span for each age group (mean digit span: 5-year-olds $=4.3$; 7-yearolds $=5.2 ; 10$-year-olds $=5.9)$, and therefore they increased with age. Five-year-olds received 9 lists of 3 items ( 3 from each word set) and 16 lists of 4 items. Seven-year-olds received 16 lists of 4 items and 25 lists of 5 items. Ten-year-olds received 25 lists of 5 items and 36 lists of 6 items. The number of intervening words between repetitions of a particular item within the memory lists was maximized. Care was taken to ensure that rhyming items were not included in the same lists.

Stimuli were presented auditorily over headphones using SuperLab Pro (Cedrus Corporation, 2001) at a presentation rate of one item every $2 \mathrm{sec}$. A row of lights provided a visual cue to the serial position of the memory items. In Condition $\mathrm{P}$, after the final list item, the target item was presented for a second time and the child pressed the button under the light representing the list position in which the target had been presented. In Condition I, after the final list item, one of the lights was illuminated and the child named the item that had occurred in that position. In Condition I, the children's responses were recorded for later analysis.

\section{Results}

One 5-year-old was removed from the sample because she responded at chance. Four 10-year-olds were removed from the sample because their scores on the BPVS were below 80 (standard score). The results for the item recall condition (Condition I) were counted as correct only if the child's response was completely accurate. Results were combined across list lengths. Separate repeated measures analyses of variance (ANOVAs) were performed for each age group (5-, 7-, and 10-year-olds) with lexicality/word set (easy words, difficult words, nonwords) as a within-participants variable. The results for position and item recall were analyzed separately because the tasks were not expected to be of comparable difficulty. Where post hoc comparisons have been made between the data for the three word types, a Bonferroni adjustment was made to the data (multiplying the $p$ value by 3 ). Figure 1 shows the proportion of correct responses by age and recall condition for the three word sets.

Condition $\mathbf{P}$ - position recall with a spoken probe. For 5-year-olds, there was a significant main effect of word set upon accuracy in identifying the position of the probe item $[F(2,38)=7.74, p<.01]$. Post hoc comparisons revealed significant differences in accuracy between easy words and difficult words $[t(19)=3.03, p<$ $.01]$, and between easy words and nonwords $[t(19)=$ $3.33, p<.01]$. The difference between accuracy for nonwords and difficult words was not significant. For 7year-olds, there was a significant effect of word set upon accuracy of position recall $[F(2,44)=3.67, p<.05]$. Post hoc comparisons revealed significant differences between easy words and nonwords $[t(22)=3.27, p<$ $.01]$, but no other comparisons were significant. For 10year-olds, there was no significant effect of word set upon position recall accuracy $[F(2,38)=2.54, p>.05]$. An ANOVA comparing the performance of the three age groups revealed a main effect of word set $[F(2,128)=$ $20.86, p<.001]$ and a significant linear component of the interaction between word set and age $[F(2,128)=$ $3.18, p<.05]$. This indicates that the effect of word set decreased with age.

Condition I-item recall with a position probe. For 5 -year-olds, there was a significant main effect of word set upon accuracy of recall of items in response to position probes $[F(2,42)=13.24, p<.001]$. Post hoc comparisons revealed significant differences in accuracy between easy and difficult words $[t(21)=4.63, p<.001]$ and between easy words and nonwords $[t(21)=3.95$, $p<.01]$. There was no significant difference between the difficult words and the nonwords. For 7-year-olds, there was a significant effect of word set upon accuracy for item recall $[F(2,46)=17.39, p<.001]$. Post hoc comparisons revealed significant differences in accuracy between easy words and difficult words $[t(23)=4.80$, $p<.001]$ and between easy words and nonwords $[t(23)=$ $5.66, p<.001]$. The comparison between difficult words and nonwords was not significant. For 10-year-olds, there was a significant main effect of word set upon item recall $[F(2,40)=35.22, p<.001]$. Post hoc comparisons revealed significant differences in accuracy for all word set comparisons: easy words and nonwords $[t(20)=$ $8.17, p<.001]$; difficult words and nonwords $[t(20)=$ $5.35, p<.001]$; and easy words and difficult words $[t(20)=3.03, p<.05]$. An ANOVA comparing the performance of the three age groups revealed a significant main effect of word set $[F(2,128)=62.4, p<.001]$ and an interaction between word set and age $[F(4,128)=$ $6.29, p<.001]$. Again, there was a significant linear component to the interaction $[F(2,128)=8.69, p<.001]$, but this time in the opposite direction. This indicates that the effect of word set increased with age.

Summary. For position recall (Condition P), the effect of lexicality upon accuracy (redintegration) decreased with age, with no effect being present for the oldest age 

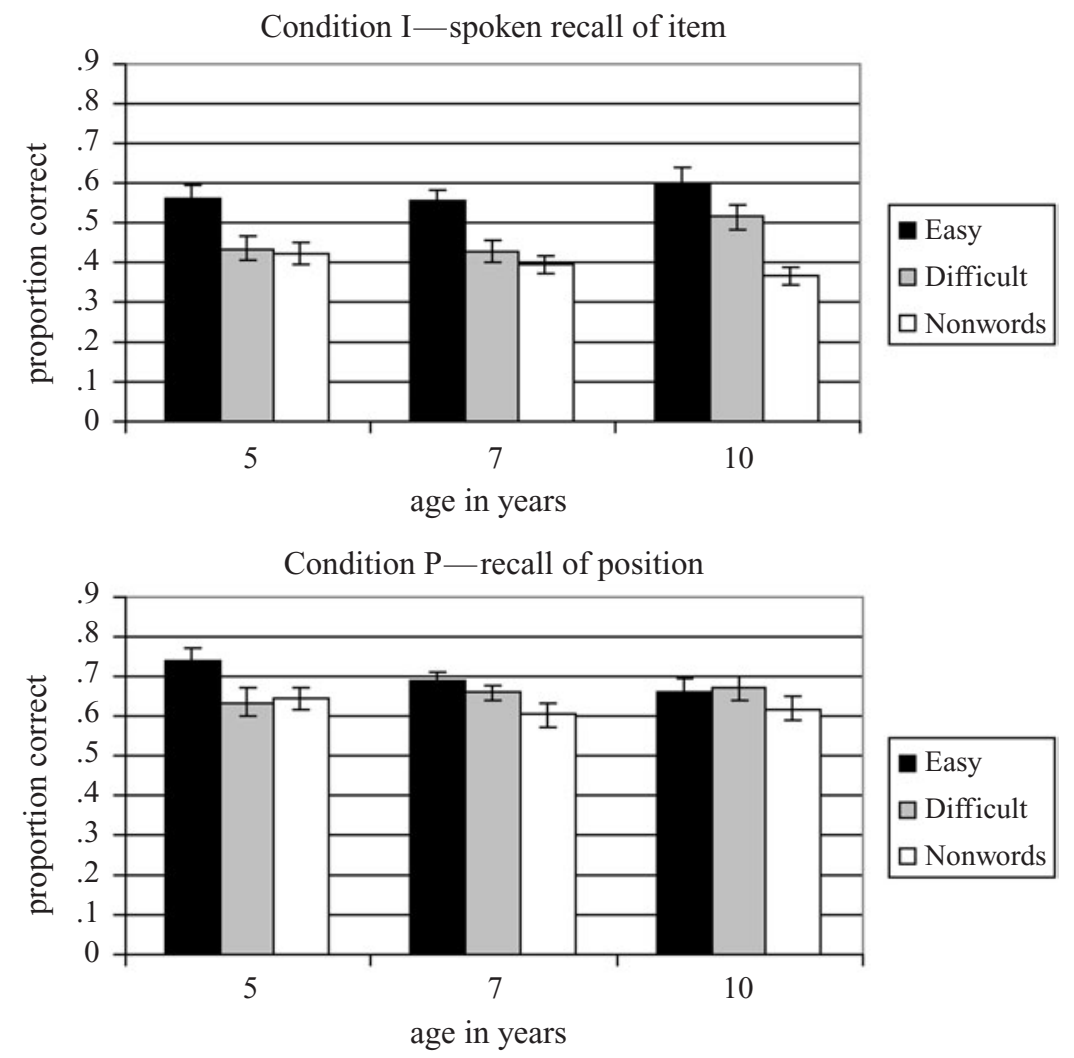

Figure 1. Experiment 1: A comparison of recall accuracy for easy words, difficult words, and nonwords by age for the two different recall methods.

group. The results for spoken item recall (Condition I) were in complete contrast, with the effect of lexicality upon accuracy being significant at all ages, and increasing with age. The use of redintegrative strategies, therefore, appeared to increase with age for the task that required that the identity of the item be remembered, whereas it decreased with age when memory for the position of the item was required. This may suggest that the younger children in the position recall condition adopted strategies that were more appropriate to item naming than to position recall. The issue of why older children use redintegration more than younger children will be addressed in the final discussion.

\section{Discussion}

In Experiment 1, we examined the effect of long-term knowledge upon recall accuracy in two memory tasks. For older children, one task resulted in the use of longterm item knowledge to enhance recall, and the other task did not. There were two main differences between the tasks: One required spoken output and the other did not, and one task involved the recall of items and the other involved the recall of positions. The use of redintegration by older children in the spoken recall task, but not in the nonspoken position recall task, could have arisen from differences in either of these task demands.
If redintegration were a property of the phonological output buffer, then it might be expected that it would be used only in tasks demanding speech. Alternatively, the use of redintegration could be dependent upon the accuracy of the memory representation needed to complete the task, as we have suggested (Turner et al., 2000). Item recall requires a reconstruction of the precise phonology of the item, whereas for position recall, incomplete knowledge of the memory items might be sufficient to complete the task. Experiment 2 was conducted to examine these alternatives. We compared the use of redintegration in a situation in which detailed knowledge of the phonology of the memory items was required, with a situation in which the task could be performed with less detailed knowledge of phonology.

\section{EXPERIMENT 2}

The memory task used in this experiment was probed recognition, in which participants were required to decide whether a probe item given at the end of the list had been present in the original list. This task does not require memory for item position. The task would not normally require detailed knowledge of the phonology of the memory list either during encoding or at output. However, rhyming probe items were included in one 
condition to create a situation in which detailed knowledge of the phonology of the list items, or of their semantics, would increase the accuracy of the decision. A measure of digit span was included to allow for an investigation of the relationship between working memory and accuracy at the recognition task.

\section{Method}

There were three memory conditions. In Condition R (rhyming), the recognition probe differed by one phoneme from one of the list items, generally rhyming with it, but was not present in the list (e.g., sound, wheat, law, trout ... POUND). In Condition N (nonrhyming), the probe was likewise not present in the list, but in this condition it did not rhyme with any list item (e.g., cliff, wheat, throw, bolt . . . BLUSH). In Condition Y (yes), the probe was present in the memory list (e.g., luck, frog, hide, home . . . FROG).

Participants. Participants included thirty 5-year-olds (mean $=$ 5 years, 4 months; $S D=3.0$ months); thirty-one 7-year-olds (mean = 7 years, 5 months; $S D=4.1$ months); and twenty-seven 10-yearolds (mean $=10$ years, 4 months; $S D=2.9$ months). Children were recruited from three schools in Surrey, England, and tested individually. They were screened using the BPVS II and were given a forward and backward digit span task taken from the WISC III (Wechsler, 1991).

Materials, Design, and Procedure. A within-participants design was used, with each participant receiving memory lists from each of the three conditions and with each of the three word sets in randomized order within each block of trials. The word sets and general procedure were the same as those used in Experiment 1.
List lengths were one item longer than in Experiment 1 since pilot tests of the task indicated that this task was easier than that used in Experiment 1.

Stimulus lists were presented auditorily. The same visual cue to serial position was used as in Experiment 1. At the end of each list, the child heard a probe and decided whether the probe had been present in the list, making a spoken "yes" or "no" response. Probes were members of the same word set as the memory list. For two thirds of the lists, the probe was not present in the list. Probes were repeated as infrequently as possible, with most occurring only once in each testing session. The serial position within the list in which the target memory item occurred in Condition $\mathrm{Y}$ and in which the rhyme occurred in Condition $\mathrm{R}$ was varied systematically.

\section{Results}

Accuracy was calculated for each condition in the form of $d^{\prime}$ using both the positive responses to nonrhyming probes and the positive responses to the rhyming probes as the false alarm rates. Figure 2 shows $d^{\prime}$ by age for the three word sets calculated for the rhyming and nonrhyming probes. Table 1 shows the hit rates and false alarm rates compared for the three age groups for each of the possible false alarm rates.

A 3-way ANOVA $(3 \times 3 \times 2$ : age $\times$ word set $\times$ rhyming/nonrhyming probe) yielded a main effect of word set $[F(2,170)=18.28, p<.001]$, with a significant interaction between word set and age $[F(2,170)=5.37$, $p<.001]$. Five-year-olds were more accurate for easy
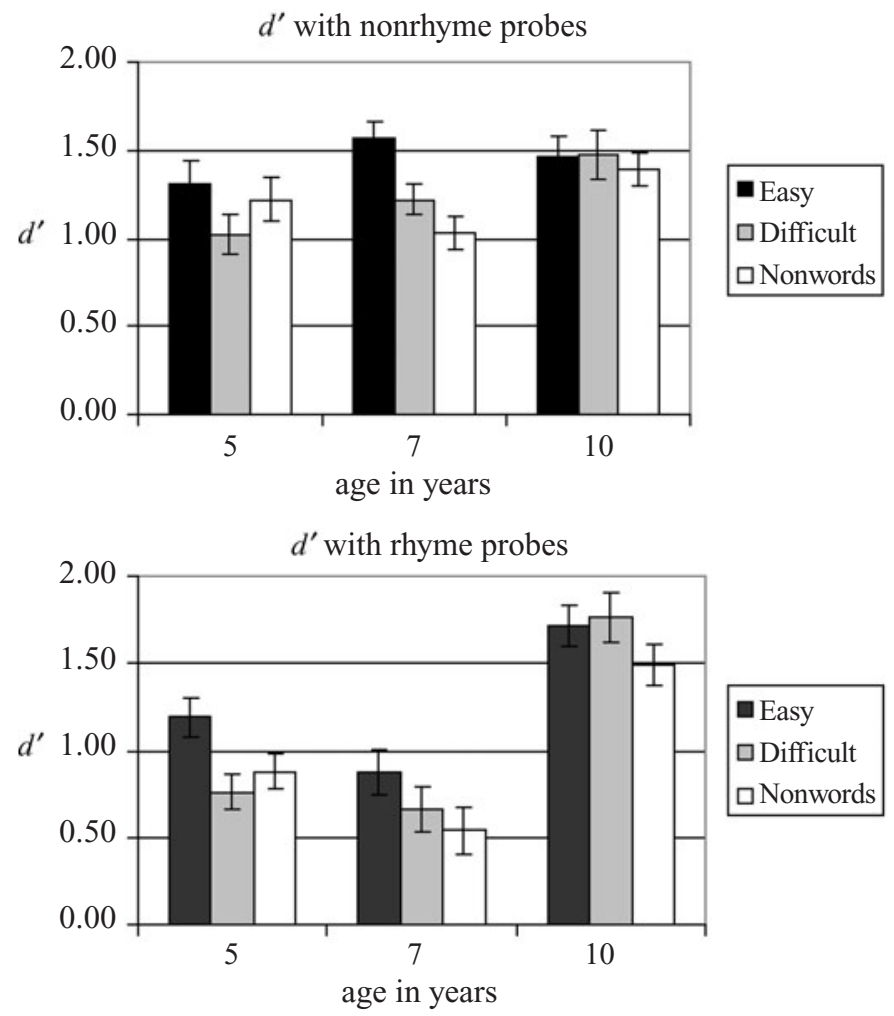

Figure 2. Experiment 2: A comparison of $d^{\prime}$ for easy words, difficult words, and nonwords by age, with a comparison of false alarms for rhymes and for nonrhymes. 
Table 1

Experiment 2 Hit Rates and False Alarm (FA) Rate Probabilities Compared for the Three Age Groups

\begin{tabular}{|c|c|c|c|}
\hline & 5 Years & 7 Years & 10 Years \\
\hline \multicolumn{4}{|l|}{ Hits } \\
\hline Easy & .65 & .69 & .80 \\
\hline Difficult & .57 & .61 & .80 \\
\hline Nonword & .62 & .54 & .79 \\
\hline \multicolumn{4}{|l|}{ FA rhyme } \\
\hline Easy & .24 & .38 & .21 \\
\hline Difficult & .30 & .37 & .21 \\
\hline Nonword & .31 & .35 & .28 \\
\hline \multicolumn{4}{|l|}{ FA nonrhyme } \\
\hline Easy & .22 & .16 & .30 \\
\hline Difficult & .23 & .20 & .30 \\
\hline Nonword & .21 & .20 & .31 \\
\hline
\end{tabular}

words and were equally inaccurate for difficult words and nonwords whereas 10-year-olds were less accurate for nonwords but equally accurate for easy and difficult words. Seven-year-olds showed orderly effects for the three word sets, with the greatest accuracy for easy words, intermediate accuracy for difficult words, and the least accuracy for nonwords. The interaction was still present when the difficult words were removed from the ANOVA $[F(2,85)=3.10, p<.05]$, and results from the relatively large word set effects at 7 years compared with the small word set effects at 5 and 10 years. There was also a main effect of rhyme $[F(1,85)=15.60, p<.001]$ and a significant interaction between rhyme and age $[F(2,85)=$ $20.05, p<.001]$, with 5 - and 7 -year-olds being more accurate in the nonrhyming condition and 10-year-olds being more accurate in the rhyme condition. There was no interaction between rhyme and word set $[F(2,170)<$ 1.0]: The effect of familiarity with the word set did not differ between the rhyming and nonrhyming probe conditions. The three-way interaction between word set, age, and rhyme was not significant $[F(4,170)=2.19, p>$ $.05]$.

Planned comparisons between accuracy for rhyming and nonrhyming probes revealed that at 5-years, accuracy for easy words did not differ significantly between the two conditions $[t(29)=1.24]$, whereas accuracy for difficult words and for nonwords was greater when the probe did not rhyme $[t(29)=3.16, p<.05$; and $t(29)=$ $3.78, p<.01$, respectively]. Seven-year-olds were more accurate for all three word sets when the words did not rhyme, as well as for easy words $[t(30)=6.38, p<$
$.001]$, difficult words $[t(30)=4.14, p<.001]$, and nonwords $[t(30)=3.55, p=.001]$. At 10 years, there was no difference in accuracy between rhyming and nonrhyming probes when nonwords were used $[t(26)=1.02]$, but for both easy and difficult words accuracy was greater when the words rhymed $[t(26)=2.26$ and $p<.05 ; t(26)=$ $2.58, p<.05$, respectively].

At 5 years, memory ability as measured by backward digit span correlated significantly with $d^{\prime}$, for both rhyming and nonrhyming probes in the easy words condition (Pearson's $r$ : easy rhyming $=.40$, easy nonrhyming $=$ .44). At 7 years, backward span correlated with $d^{\prime}$ for both rhyming and nonrhyming conditions for both easy and difficult words, and with nonwords in the rhyming condition Pearson's $r$ : easy rhyming $=.60$, easy nonrhyming $=.42$, difficult rhyming $=.54$, difficult nonrhyming $=.49$, nonword rhyming $=.51$ ). However, at 10 years, backward span correlated significantly only with $d^{\prime}$ for the easy words and difficult words in the nonrhyming conditions (Pearson's $r$ : easy nonrhyming $=.56$, difficult nonrhyming $=.50$ ). A full set of correlations is shown in Table 2.

Summary. There was an effect of the long-term knowledge of memory items upon recognition accuracy for both rhyming and nonrhyming probes: Familiar words were recognized more accurately at all ages. The 5- and 7 -year-olds were less accurate when a rhyming probe was present, whereas the 10 -year-olds used the rhyming probes to help them to remember list items and, hence, were able to reject the probe more accurately. The strategy adopted by the 10 -year-olds for rhyming probes did not depend upon their working memory capacity, whereas 5- and 7-year-olds showed a significant correlation between their performance and memory for both rhyming and nonrhyming probes.

\section{GENERAL DISCUSSION}

In two experiments, we found lexicality effects for children at all ages. These were found to be highly dependent upon the exact demands of the memory task. Several types of memory tasks, designed to require varying degrees of phonological specification for accurate performance, were examined. In Experiment 1, when the child was required to name a memory item at recall, long-term item knowledge was used to enhance recall. The more familiar the item, the more benefit the child

Table 2

Experiment 2 Pearson's $r$ Correlation Between Backward Digit Span and Accuracy of Recognition in the Three Conditions: Easy Words, Difficult Words, and Nonwords

\begin{tabular}{ccccccc}
\hline \multicolumn{1}{c}{ Age } & $\begin{array}{c}\text { Easy } \\
\text { Rhyming }\end{array}$ & $\begin{array}{c}\text { Easy } \\
\text { Nonrhyming }\end{array}$ & $\begin{array}{c}\text { Difficult } \\
\text { Rhyming }\end{array}$ & $\begin{array}{c}\text { Difficult } \\
\text { Nonrhyming }\end{array}$ & $\begin{array}{c}\text { Nonword } \\
\text { Rhyming }\end{array}$ & $\begin{array}{c}\text { Nonword } \\
\text { Nonrhyming }\end{array}$ \\
\hline 5 & $.40^{*}$ & $.44^{*}$ & .21 & .09 & .05 & .25 \\
7 & $.60 \dagger$ & $.42^{*}$ & $.54 \dagger$ & $.49 \dagger$ & $.51 \dagger$ & .23 \\
10 & .29 & $.56 \dagger$ & .21 & $.50 \dagger$ & .29 & .25 \\
\hline
\end{tabular}

Note-Correlations are shown for both rhyming and nonrhyming conditions. ${ }^{*} p<.05 . \quad{ }^{\dagger} p<.01$. 
gained at recall from its lexicality. For this task, the use of long-term knowledge was found for all the ages tested, and increased with age. In contrast, the role of long-term knowledge decreased with age when the child was required only to remember the position of a particular list item rather than its identity. Experiment 2 revealed lexicality effects for all ages in a recognition task in which the use of rhyming memory probes necessitated knowledge of the phonology of the items to produce a correct response. Together these results showed lexicality effects occurring most consistently in memory tasks for which accurate performance required a detailed knowledge of the phonological structure of the items being recalled.

Hulme et al. (1997) proposed that the effect of familiarity is a consequence of the reconstruction of an accurate phonology. Redintegration of incomplete memory traces is easier for familiar than for unfamiliar items. We found graded lexicality effects when item naming was required: The easy words (which were most familiar) were remembered the most accurately, with the difficult words (less familiar) being less accurate and the nonwords (unfamiliar) less accurate still. However, this pattern fully emerged only in the 10-year-olds. The 5-year-olds benefited from the lexicality of the easy (more familiar, earlier acquired) words, but the accuracy for the difficult (less familiar, later acquired) words was equivalent to that for the nonwords. This implies that, for the 5-yearolds, the difficult words were being processed in a very similar way to the nonwords. The rated age of acquisition for the difficult words is consistent with them being learned before 6 years of age, but it may be that our 5year-olds were only just beginning to acquire these words or had not yet developed a sufficient lexical/phonological/ semantic representation for their long-term knowledge to be useful to them in this memory experiment. For 7year-olds, the difficult words were beginning to produce lexicality effects, and these became even more marked for 10-year-olds, suggesting that this developmental process continued throughout the primary school years.

We demonstrated that phonological output is not a prerequisite for redintegration. Experiment 2 revealed lexicality effects when phonological output was not required. This result does not support the conclusion that recognition tasks necessarily produce little evidence of lexicality effects (e.g., Gathercole et al., 2001). It is not the recognition per se that eliminates the lexicality effect, but the level of phonological knowledge required to perform the memory task. If an accurate response can be achieved with partial phonological knowledge, then the role of long-term knowledge is reduced.

The possibility that some portion of the lexicality effect arises during encoding and storage cannot be eliminated. The lexicality effects found by Gathercole et al. (2001) for spoken serial list recall in 7- to 8-year-olds appear to be greater than those found for single item recall in the present Experiment 1. The requirement to recall the whole list is likely to result in a greater use of rehearsal, especially among the older children, and the greater lexicality effect may reflect a combination of the effects of lexicality upon rehearsal and upon output processes. Indeed, the increase of the effects of redintegration with age found in Experiment 1 may be a consequence of the development of the use of verbal rehearsal strategies with age (e.g., Henry, 1991; Henry, Turner, Smith, \& Leather, 2000). Verbal rehearsal, or any covert or overt repetition of the output plan (e.g., a more rudimentary form of rehearsal; Gathercole \& Hitch, 1993), may involve the repeated use of redintegration as partially remembered information is reconstructed at each iteration of the word list. The use of redintegration associated with verbal rehearsal or verbal output strategies would thus increase with age.

There were significant developmental changes in the nature of the memory tasks that resulted in the use of redintegration. Ten-year-olds used lexical knowledge to improve their memory accuracy only when detailed knowledge of memory item phonology was required. In contrast, 5 -year-olds used redintegration for all memory tasks.

One interesting result to emerge was that while the 5and 7-year-olds were less accurate when a rhyming probe was present, the performance of 10-year-olds improved significantly. A framework in which to think about children's memory performance in this task is provided by Vitevitch and Luce (1999), who drew on Grossberg, Boardman, and Cohen's (1997) adaptive resonance theory to build a model of short-term and working memory in which chunks of different size are present. For example, an English-speaking adult, on hearing $/ \mathrm{kæt} /$ (cat) might have activated the chunks $/ \mathrm{kæt} /, / \mathrm{kæ} /$, $/ \mathfrak{t} /, / \mathrm{k} /$, $/ æ /, / t /$ in STM, and depending on the task (lexical decision, rhyme detection, phoneme detection, etc.), different chunks might be selected for use in subsequent processing. Our suggestion is that young children are less able than older children to create sublexical chunks in STM. Studies of children's language development suggest that the initial phoneme is the first to be isolated (Geudens \& Sandra, 2003), so that for a 5-year-old, /kæt/ or $/ \mathrm{k} /$ might well be a chunk created in response to cat, but chunks such as $/ \mathrm{kæ} /$, /æt/, /æ/, and $/ \mathrm{t} /$ would prove difficult. A 7-year-old might have progressed to representing $/ \mathrm{kæ} /$ and $/ æ t /$, but only a 10 -year-old would have adultlike mastery of the smallest chunks.

Such a framework yields the following predictions. Faced with a memory recognition task, where cat is a previously presented target and bat and pin are newly presented distractors, the 5-year-old can compute only the overall similarity between the misleading distractors and any internal representation of the target, and thus is more likely to say bat was previously presented than that pin was previously presented, because of the overall greater similarity of cat/bat than cat/pin. The 10-yearold, on the other hand, can parse /bæt/ into chunks /b/ and /æt/, use /æt/ to reconstruct the appropriate target $/ \mathrm{kæt} /$, then note that cat and bat contain different chunks 
$(/ \mathrm{k} /$ and $/ \mathrm{b} /)$ and use this information to confidently reject the distractor bat. For the 10-year-old, pin is unlikely to evoke target items such as cat, so the rejection of pin may be made less confidently and accurately than the rejection of bat. In other words, rhyme hinders 5-year-olds and helps 10-year-olds. Our results for 7-year-olds suggest that they find rhymes even more distracting than do 5 -year-olds. There is evidence supporting this differential use of strategies by the age groups in Experiment 2 . There is a correlation between accuracy and memory ability as measured by digit span and receptive vocabulary in both the rhyme and nonrhyme conditions for 5and 7 -year-olds, but for the 10 -year-olds, correlations are mainly found for the nonrhyming condition.

In summary, two experiments have indicated that redintegrative processes are used by children as young as 5 years, but that these change in nature with development during middle childhood. For a memory task requiring spoken output, evidence for redintegration (namely, lexicality effects) increased with age from 5 to 10 years. For a recognition memory task that did not require an accurate knowledge of the phonology of the memory items, evidence for redintegration decreased with age as children presumably altered their encoding and recall strategies. When an accurate knowledge of phonology was required in a recognition task, lexicality effects were found for all ages but did not increase with age. The use of long-term knowledge to enhance redintegration was not found to be dependent upon the production of output phonology. Overall our results support the view that redintegrative processes develop with age, but in their mature form, essentially support the reconstruction of detailed phonological knowledge of words.

\section{REFERENCES}

Batyen, R. H., Piepenbrock, R., \& van Rijn, H. (1993). The CELEX lexical database (CD-ROM). Philadelphia: University of Pennsylvania, Linguistic Data Consortium.

Broadbent, D. E. (1967). Word frequency effect and response bias. Psychological Review, 74, 1-15.

CEDrus Corporation (2001). SuperLab Pro. San Pedro, CA: Author.

CowAN, N. (1999). The differential maturation of two processing rates related to digit span. Journal of Experimental Child Psychology, $\mathbf{7 2}$, 193-209.

Dunn, L. M., Dunn, L. M., Whetton, C., \& Burley, J. (1997). British picture vocabulary scale (2nd ed.). Windsor, U.K.: NFER-Nelson.

Gathercole, S. E., \& Hitch, G. J. (1993). Developmental changes in short-term memory: A revised working memory perspective. In A. F. Collins, S. E. Gathercole, M. A. Conway, \& P. E. Morn (Eds.), Theories of memory (pp. 189-209). Hove, U.K.: Erlbaum.

Gathercole, S. E., Pickering, S. J., Hall, M., \& Peaker, S. M. (2001). Dissociable lexical and phonological influences on serial recognition and serial recall. Quarterly Journal of Experimental Psychology, 54A, 1-30.

GEUDENS, A., \& SANDRA, D. (2003). Beyond implicit phonological knowledge: No support for an onset-rime structure in children's explicit phonological awareness. Journal of Memory \& Language, 49, 157-182.

Goldinger, S. D., Luce, P. A., \& Pisoni, D. B. (1989). Priming lexical neighbors of spoken words: Effects of competition and inhibition. Journal of Memory \& Language, 28, 501-518.

GregG, V. H., Freedman, C. M., \& Smith, D. K. (1989). Word frequency, articulatory suppression and memory span. British Journal of Psychology, 80, 363-374.

GrossberG, S., BOARDMAN, I., \& Cohen, M. (1997). Neural dynamics of variable-rate speech categorization. Journal of Experimental Psychology: Human Perception \& Performance, 23, 483-503.

Henry, L. A. (1991). The effects of word length and phonemic similarity in young children's short-term memory. Quarterly Journal of Experimental Psychology, 43A, 35-52.

Henry, L. A., Turner, J. E., Smith, P. T., \& Leather, C. (2000). Modality effects and the development of the word length effect in children. Memory, 8, 1-17.

Hulme, C., Maugha , S., \& Brown, G. D. A. (1991). Memory for familiar and unfamiliar words: Evidence for a long-term memory contribution to short-term memory span. Journal of Memory \& Language, 30, 685-701.

Hulme, C., Newton, P., Cowan, N., Stuart, G., \& Brown, G. (1999). Think before you speak: Pauses, memory search, and trace redintegration processes in verbal memory span. Journal of Experimental Psychology: Learning, Memory, \& Cognition, 25, 447-463.

Hulme, C., Roodenrys, S., Brown, G., \& Mercer, R. (1995). The role of long-term-memory mechanisms in memory span. British Journal of Psychology, 86, 527-536.

Hulme, C., Roodenrys, S., Schweickert, R., Brown, G. D. A., MarTIN, S., \& STUART, G. (1997). Word-frequency effects on short-term memory tasks: Evidence for a redintegration process in immediate serial recall. Journal of Experimental Psychology: Learning, Memory, \& Cognition, 23, 1217-1232.

Quinlan, P. T. (1992). The MRC pycholinguistic database. Oxford: Oxford University Press.

Roodenrys, S., \& Quinlan, P. T. (2000). The effects of stimulus set size and word frequency on verbal serial recall. Memory, 8, 73-80.

SCHWEICKert, R. (1993). A multinomial processing tree model for degradation and redintegration in immediate recall. Memory \& Cognition, 21, 168-175.

Smith, P. T., Turner, J. E., Brown, P. A., \& Henry, L. A. (2004). Redintegrative processes in children's auditory word perception. Manuscript submitted for publication.

Tehan, G., \& Humphreys, M. S. (1988). Articulatory loop explanations of memory span and pronunciation rate correspondences: A cautionary note. Bulletin of the Psychonomic Society, 26, 293-296.

Turner, J. E., Henry, L. A., \& Smith, P. T. (2000). The development of the use of long-term knowledge to assist short-term recall. Quarterly Journal of Experimental Psychology, 53A, 457-478.

Turner, J. E., Valentine, T., \& Ellis, A. W. (1998). Contrasting effects of age of acquisition and word frequency on auditory and visual lexical decision. Memory \& Cognition, 26, 1282-1291.

Vitevitch, M. S., \& Luce, P. A. (1999). Probabilistic phonotactics and neighborhood activation in spoken word recognition. Journal of Memory \& Language, 40, 374-408.

WECHSLER, D. (1991). Wechsler intelligence scale for children (3rd ed.). San Antonio, TX: Psychological Corporation. 
APPENDIX

Items Used in Experiments 1 and 2

\begin{tabular}{|c|c|c|c|c|c|c|c|c|}
\hline & \multirow[b]{2}{*}{ Neigh } & \multirow[b]{2}{*}{ AoA } & \multirow[b]{2}{*}{ Fam } & \multirow[b]{2}{*}{ Image } & \multirow[b]{2}{*}{ CELEX } & \multicolumn{3}{|c|}{$\%$ Correct at LD } \\
\hline & & & & & & 5 & 7 & 10 \\
\hline \multicolumn{9}{|c|}{ Easy Words } \\
\hline cake & 28 & 2.14 & 5.94 & 6.24 & 6 & 93 & 91 & 93 \\
\hline chain & 33 & 3.11 & 5.13 & 5.59 & 19 & 81 & 97 & 90 \\
\hline duck & 29 & 1.64 & 5.29 & 6.32 & 4 & 93 & 97 & 97 \\
\hline find & 12 & 2.72 & 5.80 & 3.70 & 292 & 89 & 94 & 90 \\
\hline fork & 26 & 2.25 & 5.84 & 5.98 & 7 & 89 & 97 & 93 \\
\hline fox & 5 & 2.83 & 5.01 & 6.07 & 6 & 100 & 97 & 97 \\
\hline frog & 6 & 2.58 & 5.07 & 6.17 & 15 & 85 & 94 & 93 \\
\hline guard & 16 & 3.44 & 5.04 & 5.30 & 10 & 89 & 94 & 93 \\
\hline hen & 20 & 2.19 & 4.61 & 5.97 & 1 & 96 & 88 & 93 \\
\hline hide & 26 & 2.56 & 5.15 & 4.30 & 1 & 93 & 97 & 97 \\
\hline home & 24 & 2.33 & 6.26 & 5.99 & 151 & 89 & 97 & 97 \\
\hline joy & 9 & 3.42 & 5.45 & 5.33 & 25 & 81 & 97 & 93 \\
\hline jump & 10 & 2.22 & 5.51 & 5.06 & 5 & 89 & 97 & 100 \\
\hline lock & 31 & 3.28 & 5.88 & 5.32 & 6 & 81 & 97 & 93 \\
\hline love & 12 & 3.03 & 6.19 & 5.69 & 128 & 89 & 97 & 97 \\
\hline luck & & 2.92 & 5.87 & 3.99 & 41 & 85 & 94 & 97 \\
\hline rhyme & 29 & 2.53 & 4.80 & 4.75 & 1 & 85 & 88 & 80 \\
\hline search & 12 & 3.44 & 5.37 & 4.02 & 18 & 85 & 91 & 93 \\
\hline snake & 10 & 2.89 & 5.01 & 6.27 & 10 & 89 & 91 & 93 \\
\hline swim & 11 & 2.56 & 5.50 & 5.72 & 8 & 89 & 94 & 97 \\
\hline touch & 14 & 2.69 & 5.90 & 4.56 & 8 & 85 & 97 & 93 \\
\hline walk & 29 & 2.06 & 6.25 & 5.05 & 35 & 93 & 97 & 90 \\
\hline wash & 14 & 1.86 & 6.32 & 5.22 & 3 & 96 & 97 & 97 \\
\hline$M$ & 18.5 & 2.63 & 5.53 & 5.33 & 34.8 & 88.9 & 94.6 & 93.8 \\
\hline$S D$ & 9.1 & .50 & .50 & .79 & 68.0 & 4.9 & 3.2 & 3.9 \\
\hline \multicolumn{9}{|c|}{ Difficult Words } \\
\hline bet & 32 & 3.64 & 5.27 & 4.53 & 7 & 74 & 81 & 83 \\
\hline bite & 38 & 2.14 & 5.93 & 5.53 & 2 & 70 & 97 & 93 \\
\hline blush & 7 & 3.78 & 5.35 & 5.51 & 0 & 30 & 69 & 83 \\
\hline boast & 17 & 3.78 & 4.91 & 4.16 & 1 & 41 & 72 & 97 \\
\hline bolt & & 3.69 & 4.66 & 5.51 & 3 & 56 & 75 & 87 \\
\hline cliff & 6 & 3.22 & 4.79 & 5.99 & 7 & 63 & 100 & 97 \\
\hline crew & 17 & 3.66 & 4.42 & 4.86 & 14 & 67 & 94 & 93 \\
\hline crush & 5 & 3.39 & 4.80 & 4.80 & 0 & 74 & 91 & 93 \\
\hline force & 26 & 3.72 & 5.52 & 4.37 & 186 & 59 & 91 & 93 \\
\hline grip & 13 & 3.25 & 5.23 & 5.40 & 1 & 41 & 88 & 87 \\
\hline growth & 6 & 3.78 & 5.60 & 4.26 & 72 & 22 & 44 & 83 \\
\hline law & 21 & 3.83 & 5.62 & 4.09 & 423 & 30 & 78 & 80 \\
\hline pound & 8 & 3.08 & 6.18 & 5.53 & 89 & 78 & 97 & 93 \\
\hline raid & 39 & 3.91 & 4.87 & 4.76 & 2 & 22 & 34 & 77 \\
\hline scout & 10 & 3.72 & 4.52 & 5.78 & 8 & 26 & 72 & 83 \\
\hline shrub & 3 & 3.83 & 4.46 & 5.56 & 0 & 33 & 53 & 60 \\
\hline sigh & 17 & 3.80 & 5.18 & 4.40 & 1 & 44 & 84 & 77 \\
\hline sound & 9 & 3.00 & 5.97 & 4.97 & 130 & 74 & 97 & 100 \\
\hline throw & 10 & 2.64 & 5.48 & 4.77 & 8 & 70 & 94 & 97 \\
\hline trout & 3 & 3.94 & 4.79 & 6.17 & 1 & 22 & 66 & 73 \\
\hline weep & 26 & 3.56 & 4.55 & 5.23 & 0 & 19 & 56 & 93 \\
\hline wheat & 40 & 3.86 & 5.10 & 5.77 & 17 & 56 & 94 & 83 \\
\hline wreck & 25 & 3.69 & 5.16 & 5.95 & 2 & 63 & 88 & 93 \\
\hline$M$ & 17.2 & 3.52 & 5.14 & 5.13 & 42.3 & 49.3 & 78.8 & 87.0 \\
\hline$S D$ & 12.1 & .45 & .50 & 63.7 & 96.1 & 20.5 & 18.2 & 9.5 \\
\hline \multicolumn{9}{|c|}{ Nonwords } \\
\hline borv & & & & & & 92.6 & 90.6 & 96.7 \\
\hline brin & & & & & & 70.4 & 59.4 & 83.3 \\
\hline chay & & & & & & 77.8 & 93.8 & 90.0 \\
\hline doy & & & & & & 85.2 & 81.3 & 86.7 \\
\hline drus & & & & & & 77.8 & 87.5 & 96.7 \\
\hline fowt & & & & & & 85.2 & 96.9 & 90.0 \\
\hline frod & & & & & & 81.5 & 81.3 & 83.3 \\
\hline frug & & & & & & 74.1 & 96.9 & 96.7 \\
\hline gayd & & & & & & 81.5 & 93.8 & 80.0 \\
\hline grut & & & & & & 92.6 & 87.5 & 83.3 \\
\hline gud & & & & & & 70.4 & 78.1 & 93.3 \\
\hline hok & & & & & & 63.0 & 84.4 & 80.0 \\
\hline
\end{tabular}


APPENDIX (Continued)

\begin{tabular}{|c|c|c|c|c|c|c|c|c|}
\hline & \multirow[b]{2}{*}{ Neigh } & \multirow[b]{2}{*}{ AoA } & \multirow[b]{2}{*}{ Fam } & \multirow[b]{2}{*}{ Image } & \multirow[b]{2}{*}{ CELEX } & \multicolumn{3}{|c|}{$\%$ Correct at LD } \\
\hline & & & & & & 5 & 7 & 10 \\
\hline lowv & & & & & & 85.2 & 93.8 & 96.7 \\
\hline poi & & & & & & 66.7 & 90.6 & 90.0 \\
\hline rike & & & & & & 81.5 & 87.5 & 96.7 \\
\hline rowk & & & & & & 77.8 & 84.4 & 93.3 \\
\hline rorj & & & & & & 81.5 & 81.3 & 96.7 \\
\hline shive & & & & & & 74.1 & 93.8 & 96.7 \\
\hline skrond & & & & & & 81.5 & 96.9 & 96.7 \\
\hline sowt & & & & & & 77.8 & 90.6 & 86.7 \\
\hline stuv & & & & & & 81.5 & 96.9 & 96.7 \\
\hline tud & & & & & & 81.5 & 87.5 & 93.3 \\
\hline twun & & & & & & 74.1 & 96.9 & 86.7 \\
\hline$M$ & & & & & & 78.9 & 88.3 & 90.9 \\
\hline$S D$ & & & & & & 7.11 & 8.41 & 5.83 \\
\hline
\end{tabular}

Note-Neigh, phonological neighbors (Roodenrys, unpublished); AoA, subjective age of acquisition; Fam, familiarity; Image, imageability (all from the MRC Psycholinguistic database, Quinlan, 1992); CELEX, spoken frequency (Baayen, Piepenbrock, \& van Rijn, 1993). Percent correct at lexical decision (LD) is accuracy data by age group, taken from Smith et al. (2004).

(Manuscript received November 17, 2002;

revision accepted for publication October 2, 2003.) 